\title{
The Institutional Logic of Regional Modernization of Higher Education
}

\section{L.L. XIE}

The School of Public Policy and Management, Tsinghua University, Beijing, China

The School of Management Science \& Industrial Engineering, Guangxi University of finance and Economics, Nanning, Guangxi, China

C. HUANG \& Y. G. WEI

The School of Public Policy and Management, Tsinghua University, Beijing, China

\begin{abstract}
Modernization of higher education is a process involving the political, economic and cultural aspects and affecting the whole society. This paper aims to build an ideal model of modern higher education with the features of political empowerments, economic drivers, and cultural construction. For this end, this study adopted an institutional perspective and a systematic analytic method. This study respectively investigated the driving forces and impediment factors for regional higher education modernization in the economic, political and cultural aspects. Policy recommendations are provided for the government to improve the regional modernization of higher education. The policy suggestions include strengthening the scientificity of the political empowerment, improving the timeliness of interest-driven, and promoting concept reconstruction.
\end{abstract}

KEYWORD: Regional modernization of Higher Education, The Layout Structure of Higher Education, Institutional Logic

\section{THE INSTITUTIONAL ANALYSIS OF MODERNIZATION OF HIGHER EDUCATION AND LAYOUT STRUCTURE}

The modernization of higher education implies that the higher education plays an important role in the social development, economic growth and human resource development. As a result, the modernization of higher education is motivated by politics, economics, culture, history and other factors. It is a sustainable process to improve the internal structure and external system of higher education [1]. In achieving this improvement, the inner motivation of higher education development is the requirement of politics, economics and culture development. Nevertheless, the asynchronization of higher education and social development reflect potential obstacle and impediment between internal and external systems. Therefore, an tool is needed to analyze the problems existed in these systems. As of 1990s, the paradigm of new institutionalism is widely used in analyzing economics, politics and sociology etc. It is an empirical methodology of researching social and politics as well as individual's life, which places high value on institutional factors [2]. As a part of social modernization, the development of higher education could be studied by the paradigm, analyzing the political, economic and cultural factors, all of which contribute to establishing a higher educational system that suits social modernization.

This study focus on the regional higher education layout structure in modernization, by studying the driving force and impediments within each institutional factor, as well as the institutional logic in higher education modernization, and developing a ideal model of higher education modernization. Considering the stability of the layout structure in higher education, it mirrors the interaction among higher education and other sectors. "For all the organizations, it is not only necessary to keep the stability, but also the adaptability to the surroundings so as to fulfill their functions"[3]. Thus, the modernization of higher education positively interplays with its layout structures. The interactive outcome is a well-running layout structure brings into full play of higher education in the social modernization of high education. Hence in this study, an ideal model will be built at theoretical level by institutional analysis, following by viewing the driving forces and impediments in higher educational modernization from geographic structure, discipline structure, nature of school running, and hierarchical structures. By doing this, the significance of institutional logic in higher educational modernization will be concluded. Based on the conclusion, policy implication will be 
proposed in order to forge ahead the higher educational modernization.

\section{THE CONSTRUCTION OF THE IDEAL MODEL OF HIGHER EDUCATION MODERNIZATION}

From an institutional perspective, "the main players of the modern economic and political system are different official organizers; the legal institutions and different bureaucracies play the key roles in the contemporary society"[4]. To achieve the modernization of high education, tertiary education related social departments, such as, government, enterprises, social organizers should function more positive effects by means of cultivating behavioral incentives and individual preferences of the citizens. It means that the institutional systems in different fields should function as the diving force to promote the modernization of high education. The diving force refers to "institutional logics". In the process of high education modernization, the high education industry and different colleges and universities face a macro "institution" system, including regulatory power, normative constraints, and conceptual cognitive framework. These factors constitute the institutional logics of high education modernization.

\subsection{University institutions work as the regulatory powers in the political system}

"Rules and regulations" are an agreement covering different areas with different extents of binding effects, and they are a series of explicit and implicit rules, patterns, regulations and decision procedures. Due to the existence of "rules and regulations", actors' expectations intermingle and unify in certain filed. Political powers endeavor to realize the political goal of the whole society modernization, by entitling colleges and universities, education authorities, enterprises, and different organizations powers and authorities. These powers and authorities often work through the forms of administrative commands, policy documents, or legal effects. Once these policies and regulations are determined and implemented, the concerns and behaviors of related stake-holders will be unified and be adjective to similar choices and expectations. Political entitlements are the primary driving force of high education modernization. The entitlements of authorities include powers and legality that universities and related departments necessitate to improve high education modernization.
2.2 In the economic field, university institutions are per se a whole of the forms of capital and constraint regulations

Although political entitlements serve to achieve the political goals of national development, they also aim to meet the economic social demands from high education modernization. Policies are the reflection of the economy, and the ultimate goal of political entitlement is to maximize modern economic benefit. Compared to political demands, economic forces are the most direct interests and incentives. This type of regulations works as capital to support the faith and credits among individuals. More important is that it can effectively avoid individual and organization's potential losses during the process of supporting other's short-term benefits. Therefore, political entitlement uses the compulsory order to "command" the modernization reform of high education. In the economic filed, political entitlement uses the regulatory constraints to guide colleges and universities to act accordingly. Institutions, as a form of capital, are a commonly followed regulation. Colleges and university cannot find the legal development rooms and benefit related stakeholders, without following the modernization process. Therefore, political entitlements are the original driving forces for China's high education modernization, and economic benefits are the incentives for promoting high education development.

\subsection{From a cultural perspective, colleges and universities are per se an organization}

The development logics of colleges and universities include not only the political and economic demands, but also the cultural rules. These rules embody through actors' concept. From an institutional perspective, culture is an important institution, and concept is its presentation form. Culture is an important decision factors for policy development and institution choices. It is "a resource for political cooperation, an approach for legalization for political behaviors, a cognitive framework for policy choice configuration, a policy tool, and a catalyst for institutional transition". The most important task for high education modernization is to change habits of thinking, because institution includes not only formal regulations, procedures and norms, but also cognitive regulations, and moral models. Actors' understandings on the concepts of high education modernization are per se the common concepts and attitudes of high education organization. They form a conceptual framework to guide the actors' behaviors. In the framework, actors seek to achieve the legality of implementing high education modernization. Meanwhile, they search for behavior form supports for their actions and exclude the counter- 
modernization factors. It is concluded that culture is the sustainable forces to support the high education modernization.

To investigate the modernization of higher education in the fields of politics, economy and culture through institutional analysis, the modernization of higher education could be defined as taking action by political empowerment, realizing the modernization by economic drive and the longterm support of the idea of modern higher education.

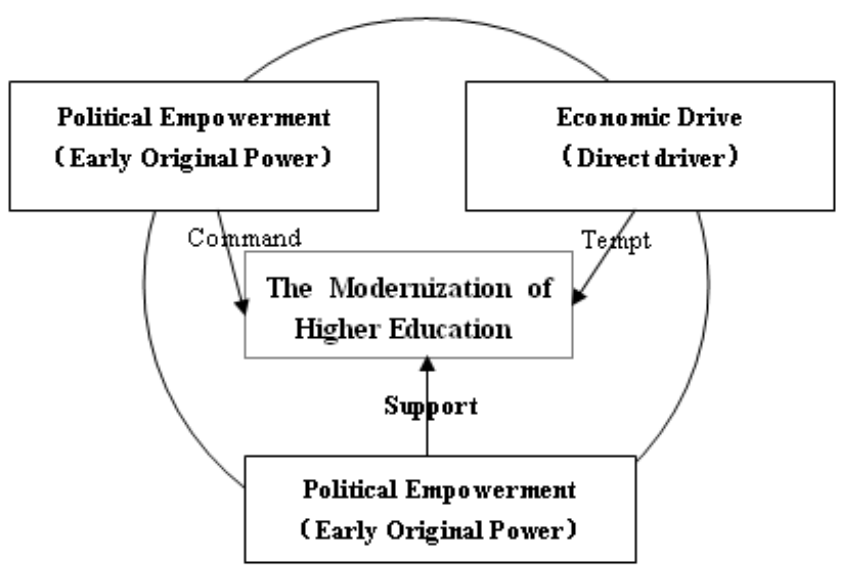

Figure 1 The ideal model of the modernization of higher education

The figure 1 shows an ideal system of the modernization of higher education, and the running of the system needs the supports of politics, economy and culture. Based on the administrative order, policy document and the regulation of the law, the politics become the original power of the modernization of higher education through the empowerment. The higher education is regard as the direct engine of capital through profit-oriented, efficiency incentive and quality control. However, the precondition of these two fields includes the respect for cultural development, the construction of modern belief inside and outside the higher education system and the guarantee taking the action under the framework of "modern". This model includes the data certification from the perspectives of politics, economy and culture from the modernization of higher education.

\section{DISCUSSION}

In fact, if we take the adjustment of the structure as the pointer of the higher education function modernization, then its motivation and obstruction will both stay in the whole institution of social system, which is the political power, the economical benefit, as well as the cultural opinion. Political empowerment, economical motivation and cultural constitution will be the three institutional logic of the region higher education modernization's progress. This theoretical model shows us the problems and shortage of the higher education modernization in China, from which we can analyze the problems and hit the key to make up the solutions of the region higher education modernization.

\subsection{The scientism of enhance political empowerment}

The political empowerment is the original motivation of the higher education modernization, the local government under the Chinese administration and its department of education does well in leading the universities' action to legitimate by empowerment. There is no doubt that the political empowerment plays the role as decisive impetus in China, however, regulatory power's function also faces the obstruction of less of scientism. Therefore, we need to pay attention to the scientific verification before as well as after the political empowerment.

" Every education policies must research and analyze many implicit assumptions that are concluded in the concerned of science and explicit modern about the nature of science and society, which means educational policies with theoretical guidance that really at the height of epistemology." Otherwise the lack of "feasibility argument" before policy introduced, "infeasibility argument" after policy introduced; too much of the positive influence studies in the process of policy implementation and post-implementation, lack of negative influence studies. These policies which only show problems but lack of theories are apart from the reality, it's hard to imply and easy to fail in the half way because of the uncertain. Function of higher education take a longer time period, education itself should have an "advanced", the uncertain of the policies does nothing good to the stabilized form layout structure of higher education, can't play a leading role in higher education either. In accordance with the theoretical model and practical demonstration, first of all, fix ideas, and then identify the problem, then policies, finally, supervision and feedback, do the valuation before, in, and after the policy implementation, so that we can strengthen the scientific of the political empowerment. It might also be noted that it's just the political power that start with action, rather than the signs of Higher Education Modernization don't start in the political field, economic interest is the direct driving force for modernization, we should follow up the motivation for the higher education from the economic benefits.

\subsection{Improve the timeliness of the profit driven}

With the realization of the modernization of higher education, the relationship between the Institutions of higher learning and the economic field become 
closer. But enhancing the economic benefits of higher education isn't or shouldn't be the purpose of the higher education modernization, instead, we should improve university organization effectiveness means, to improve the function of the organization in a better way, improve the quality of the products. Nowadays, one of the maximum resistances of the higher education modernization is the lack of support from the economic field for the higher education modernization. Canadian government always view higher education as an investment rather than spending, which means economic field need a large of infusion of fund at first, then there is the realization of the modernization of higher education, only in this way can exert the function of higher education to nurture society. But after all, higher education is part of the field of culture, if we simply chase economic effects, it might be give a lark to catch a kite or lose the life source of the higher education's nature; simple conception of culture construction is also apart from practice easily and lose its foundation, push the universities even far away from the society and market. Therefore, the implementation of the higher education modernization needs the economic motivation and the culture construction to overcome the resistance of profit-driven.

\subsection{Emphasis on sustainability of the construction of the concept}

Use Investigate the region higher education Present Situation of the layout structure and the institutional logics, analyze the relationship between the resistance of the region higher education progress and the modern concept construction. It's impossible to realize the advanced and relatively stability of the higher education layout structure without the concept of the modern higher education, and it may neither respect the development regulation of the higher education. Concept/culture is important part of the higher education modernization institutional logic, the cognitive network such as the long-standing values, habits and customs and so on provide the meaning framework of the "higher education modernization " for the university actors, constraints on people's behavior, only in this way can we overcome the modernization resistance, that subject and major stay apart from the market, the lack of demand for the higher vocational colleges, private colleges and universities, as well as lack of high-level personnel training. Therefore, we should emphasis on organization, structure, culture, norms, the process of customs constitute social behavior, as well as the process and the results of the distribution of power between the actors, during the implementation of the higher education modernization progress. What's more, we need to pay attention to the persistence of the higher education concepts construction. We should establish long-term mechanism of cultural thought construction, step by step, which leads to the formation of a scientific and rational modern development pattern and behavior patterns of higher education in people's thinking and understanding eventually. All in all, the region higher education modernization should be the whole society operating system that takes the political empowerment as the leader, the economical motivation as the impetus, the concepts construction as the guarantee, thus we can make the higher education modernization be an integral part of the whole society modernization.

\section{ACKNOWLEDGEMENTS}

The first author wishes to thank the National Social Science Fund of China (12CGL090) and The Training Project for Outstanding young teachers in the Colleges and universities of Guangxi for the financial support.

\section{REFERENCES}

[1] "Index study of Shanghai higher education modernization" project team (abbrev. ISSHEM). 2007. The forecast of the frame and index of Shanghai higher education modernization. Exploring Education Development 2007(02): 17-23. (In Chinese)

[2] Xue X.Y. \& Chen J. G., 2004. Globalization and NeoInstitutionalism. Beijing: Social Sciences Academic Press (In Chinese).

[3] FFremont E. K, and James E.R. 2002. Organization and Management. McGraw Hill. Inc.

[4] March, J.M. \& Olsen, J. P. 1984. The new institutionalism: Organizational factors in political Life, The American Political Science Review, 78(3): 734-749. 